\title{
The Sociometric Science of Disease: The Ultimate Who Shall Survive in Sociometric Epidemiology
}

\author{
Rory Fleming Richardson* \\ Clinical Medical Psychologist \& Neuropsychologist, ABMP, Malaysia
}

*Corresponding author: Rory Fleming Richardson, Clinical Medical Psychologist \& Neuropsychologist, ABMP, TEP, George Town, Pulau Pinang, Malaysia

\section{Introduction}

In 1934, Jacob L. Moreno, M.D. published his ground-breaking book Who Shall Survive?Foundations of Sociometry, Group Psychotherapy, and Sociodrama.Dr. Moreno was a contemporary of Freud, Adler and Jung pioneering the study of social dynamics and the therapeutic power of "live and therapy in action." Today, we have a challenge that few are prepared for. We are an extremely mobile civilization with interaction with others and environments that others contact. If one person touches the handle to enter a store, how many other people touch that handle? If you count the number of people one person is within two feet of in a 24-hour period, how many would that be? One of the saving graces of most infections is that there is a short incubation period. This means that within a short period a person would know that they are ill and be able to limit exposing others. For those who design biological weapons, long, asymptomatic incubation periods are best to insure the spread of an infection. The longer the time that the incubation period is, the more individuals can spread it and the less prepared communities and countries are in limiting the spread. If we use the science of sociometry with the science of epidemiology, we start to understand the scope and the obstacles to prevention of epidemic and pandemic concerns. I find it interesting that Dr. Moreno entitled his book Who Shall Survive? in 1934 when the application in today's world is so profound[1].

Let us examine how sociometric epidemiology works. A person goes to a major airport to catch a flight on a business trip. Besides those within the breathing distance of that person, there are key places of infection. In sociometry, a sociometric star is one who is chosen most by others. If we expand this to things where pathogens can be exchanged, we start to see the risk. The infected person enters the airport, goes to the ticket counter, has a coffee, sits in the waiting area, and goes to the restroom. The sociometric stars would be the hands on the doors in the airport, the money given to the coffee shop, the counter where he/she picked up the coffee, the creme and sugar counter, the chair in the waiting room, and the handle on the restroom (both in and out). How many individuals would touch the same areas without washing their hands before they touch their face? If the infected person is asymptomatic, there are hundreds infected even before you count the individuals in close proximity or on the plane. Depending on the pathogen and the incubation period, it becomes very easy to understand the potential of a pandemic and the tendency of the public to underestimate risk.

Depending on the pathogen and transmission, there are other sociometric stars. As anyone who has knowledge of air exchange systems knows, specific filtering is needed for various pathogens. Unfortunately, not all commercial entities invest and maintain the best equipment. If we were to diagram pathogen droplet flow and concentrations, there are locations which are at higher risk. Also, money changing comes another location for sociometric stars. The cash registers may become petri dishes.There are some high contamination towns that are likely to suspend use of paper money and coinage. It would be an error in thinking to believe that in a world where nanotechnological medicine and pathogens [2] exist accidental or intentional use of both may not result in mutations which do not operate on the level of a standard infection. Making assumptions about the viability of a pathogen without monitoring a significantly extended time period could easily result in placing additional individuals at risk. In addition, standard laboratory testing may inadvertently show false negatives. Although this is quickly brought to like, potential carriers of an infection can be release back into circulation.

In itself, the natural evolution and mutation of pathogens represent a diverse profile which is more than challenging for healthcare providers. When combined with current technology, development of pathogens useful in biochemical warfare poses a profound challenge. Although there are some providers who have training in treating biochemically infected patients, most have very 
little training or orientation.During the last two decades, efforts were taken to train at least one individual in each hospital in the use of hazmat protocols.

The history of biological weapons can be traced back to 1155 Tortona, Italy when Emperor Barbarossa poisoned well water with human bodies. During the first and second World Wars, the use of biological weapons grew. In 1969, the United Nations' disarmament forum discussed the concerns about biochemical warfare. One of the problems with weaponized biological pathogens is that, unlike troops, they are not aware of or recognize country borders. On April 10, 1972, Biological Weapons Convention (BWC) created a legally binding treaty that outlaws' biological arms [3]. As of August of 2019, 183 countries have agreed to the BWC. Through the various conventions, the one caveat to the agreement is that biological agents can be collect (stockpiled) for "prophylactic, protective or other peaceful purposes." Over the same period of time, the development and blending of various other sciences occurred. We developed a better understanding of nanotechnology, ways of utilizing nanotechnology in medicine, and engineer ethnically targeted pathogens based on DNA. Most individuals thing of this level of technological development as science fiction, but the knowledge base of these technologies is significant and growing.

Regardless of agreements and protective protocols, accidents can occur resulting in threats to human and animal life. One of the unfortunate realities is that it is easier to develop a pathogen that to develop a cure. Regardless of the intent or development of a pathogen, it can result in a pandemic.More complicated pathogens can impact type of contagion (i.e., airborne, tactile, droplets, fluid exchange, etc.), its life span, and other factors making prevention and control a nightmare. These variables alter the sociometric epidemiologic dynamics. It is essential that the sociometry of the individuals, the pathogens, and the environment be fully considered in the prevention and control of disease.

The next element of sociometric epidemiology is examining the sociodynamic factors which support or negate containment. In olden times when the best modes of transportation were on foot, in carts, or on ships, spread of a contagion was limited because of the amount of time which it took people to get outside a catchment area. Also, communication was limited by the same constraints. If a pathogen showed symptoms within a week, the contagion could be isolated. This is what resulted in "plague ships" which were held off coast rather than being allowed to land. Today, people from Southeast Asia can be in the USA within 32 hours via air travel.
Depending on the speed of response, many contagions can be limited.What are the sociodynamic factors which impact this? It is an issue of controlling the information. If a government does not want to instill a panic, information may be controlled minimizing the risk so that countermeasures can be put in place to limit those who could move outside the catchment area. The trade-off is that this delays appropriate response by healthcare professions. Another factor is the impact on economics. If a contagion is identified, it will impact the movement of consumers and products to the

point of halting commerce. Rather than a motivation which may be based on common good, the motivation is more likely because of greed, profiteering, or fear of unwanted consequences. The trade-off is that the very consumers who would purchase items are likely to become infected and, in the long term, be removed from the equation. Epidemiologically speaking, the best action would be to isolate the individuals who are connected to the sociometric stars. Sanitizing sociometric star locations while not isolating the individuals connected to those areas is just likely to reinfect the areas and spread the disease.It is very easy to see how the expanded, sociometric approach to epidemiology can introduce more complex factors which are at play in the spread of disease. As we move towards faster mobility and the incubation period for infections are counted in days and weeks rather than hours, our ability to enhance our understanding of these factors becomes even more important.

If one is dealing with a highly contagious, mutating pathogen, it is better to look at the pathogen itself as the infected carrier. By doing this, the matrix of risk is inclusive of the places, things and people that the pathogen contacts. If one only looks at active cases (human), it is like the turtle trying to catch up with a hare. The result is an ever-increasing pandemic. Preventative epidemiology using this sociometric matrix of the pathogen will shut down daily functions quickly and have far reaching economic impact, but it is the one sane action to minimize loss of human life. In the long run, normal life and societal function will return sooner.

\section{References}

1. Moreno JL (1953) Who shall survive?: Foundations of sociometry, group psychotherapy and sociodrama. JAMA 153(14): PP1326.

2. Cui Z (2014) Interdisciplinary Research of Virology and Nanobiology. Austin Virol and Retrovirology 1(1): PP2.

3. Frischknecht F (2003) The history of biological warfare. Human experimentation, modern nightmares and lone madmen in the twentieth century. EMBO Rep 4 Spec No (Suppl 1): S47-S52. 
CC (P) This work is licensed under Creative

To Submit Your Article Click Here:

Commons Attribution 4.0 License

DOI: 10.32474/OJNBD.2020.04.000176

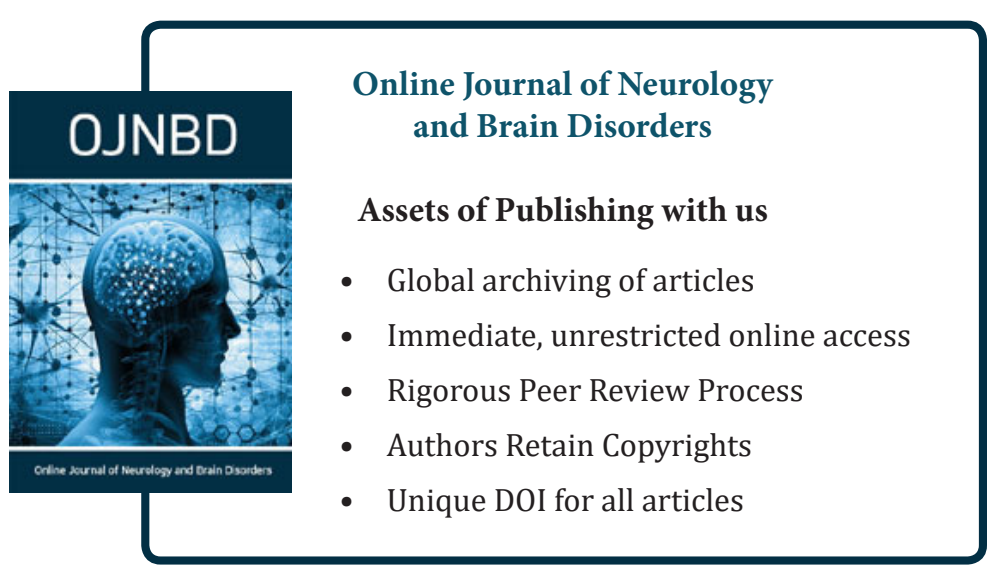

